\title{
Corrigendum to "Antiapoptosis and Antifibrosis Effects of Qishen Granules on Heart Failure Rats via Hippo Pathway"
}

\author{
Jian Zhang $\mathbb{D}$, ${ }^{1}$ Junjie Liu $\mathbb{D}^{2},{ }^{2}$ Sheng Gao $\mathbb{D}^{3},{ }^{3}$ Weili Lin $\mathbb{D}^{3},{ }^{3}$ Pengrong Gao $\mathbb{D},{ }^{4}$ Kuo Gao $\mathbb{D},{ }^{4}$ \\ Yili Zhang $\mathbb{D}^{4}{ }^{4}$ Kangjia Du $\mathbb{D}^{4}{ }^{4}$ Xiaomin Yang $\mathbb{D}^{1},{ }^{1}$ Wei Wang $\mathbb{D}^{4},{ }^{4}$ Ruixin Zhu $\mathbb{D}^{3}$ \\ and Yong Wang $\mathbb{D}^{1}$ \\ ${ }^{1}$ School of Life Science, Beijing University of Chinese Medicine, Beijing 100029, China \\ ${ }^{2}$ Dongzhimen Hospital, Beijing University of Chinese Medicine, Beijing 100700, China \\ ${ }^{3}$ School of Life Sciences and Technology, Tongji University, Shanghai 200092, China \\ ${ }^{4}$ School of Traditional Chinese Medicine, Beijing University of Chinese Medicine, Beijing 100029, China \\ Correspondence should be addressed to Yong Wang; wangyong0201@163.com
}

Received 8 June 2020; Accepted 9 June 2020; Published 10 July 2020

Copyright (c) 2020 Jian Zhang et al. This is an open access article distributed under the Creative Commons Attribution License, which permits unrestricted use, distribution, and reproduction in any medium, provided the original work is properly cited.

In the article titled "Antiapoptosis and Antifibrosis Effects of Qishen Granules on Heart Failure Rats via Hippo Pathway" [1], there was an error in Section 2.5 "Measurement of Serum Biochemical Markers" of the article body. Section 2.5 "Measurement of Serum Biochemical Markers" should be updated as follows:

Measurement of Serum Biochemical Markers:

At the end of the cardiac function examination, rats were anesthetized with $1 \%$ pentobarbital sodium $(50 \mathrm{mg} / \mathrm{kg})$ by intraperitoneal injection, and blood samples were collected from the abdominal aorta and centrifuged at $1000 \times \mathrm{g}$ for 20 min to obtain serum.Serum levels of ALD and PIIINP were measured by radioimmunoassay. BNP, ANP, MMP-2, and MMP-9 were detected by enzyme-linked immunosorbent assay following the instructions of kits (Fanke Biological Technology Company, Shanghai, China).

\section{References}

[1] J. Zhang, J. Liu, S. Gao et al., "Antiapoptosis and antifibrosis effects of Qishen granules on heart failure rats via Hippo pathway," BioMed Research International, vol. 2019, Article ID 1642575, 13 pages, 2019. 